\title{
DETERMINANTS OF THE IMPLEMENTATION OF THE PUBLIC-SECTOR CONSOLIDATED FINANCIAL STATEMENTS IN VIETNAM
}

\author{
Yen Thi Tran¹, Thanh Thi Cam Tran², Trang Cam Hoang ${ }^{3}$ \\ ${ }^{1}$ School of Accounting, University of Economics Ho Chi Minh City, Vietnam, 59C Nguyen Dinh Chieu st., District 3, \\ Ho Chi Minh City, Vietnam \\ ${ }^{2}$ Faculty of Economics and Accounting, Quy Nhon University, 170 An Duong Vuong, Quy Nhon city, Vietnam \\ ${ }^{3}$ Faculty of Finance and Banking, Ton Duc Thang University, 19 Nguyen Huu Tho Street, Tan Phong Ward, \\ District 7, Ho Chi Minh City, Vietnam
}

Link to this article: https://doi.org/10.11118/actaun202068050903

Received: 6. 2. 2020, Accepted: 29. 9. 2020

To cite this article: TRAN YEN THI, TRAN THANH THI CAM, HOANG TRANG CAM. 2020. Determinants of the Implementation of the Public-Sector Consolidated Financial Statements in Vietnam. Acta Universitatis Agriculturae et Silviculturae Mendelianae Brunensis, 68(5): 903-913.

\begin{abstract}
The purpose of this study is to identify factors that affect the implementation of the consolidated financial statements (CFS) of the public sector in Vietnam. The study also presented some of the benefits and challenges of implementing CFS in the view of some experts in Vietnam. The majority view of experts thought that the implementation of CFS in the public sector has many benefits, including a financial clarification of the public sector. Nevertheless, Vietnam will face difficulties when implementing CFS such as human resources, infrastructure, and financial resources. The results of the quantitative analysis showed that accrual accounting basis, accounting staff capacity, regulatory environment, and information technology significantly influenced the implementation of CFS of the public sector in Vietnam. The study contributes significantly to theory and practice as Vietnamese policy makers recently issued Decree No. 25/2017/ND-CP on CFS for the public sector. This Decree takes effect from January 1, 2018.
\end{abstract}

Keywords: consolidated financial statements, benefits, challenges, Decree No. 25/2017/ND-CP, public sector, Vietnam

\section{INTRODUCTION}

Over the last two decades, many western countries have been engaged with managerial reforms inspired by new public management (Tagesson and Grossi, 2012). These reforms have had a great influence on the development of public accounting and reporting systems. The most important reform that took place in the public sector is the movement from a cash-based accounting system to an accrual one (Adhikari and Mellemvik, 2011). The introduction of accrual accounting in the public sector entities represents a first step towards the introduction of a new reporting system in the public sector, namely the consolidated reporting system.
The public-sector consolidated financial statements represent a challenging topic of worldwide research and has also become a debated issue both for the international regulatory body (IPSASB) and for governments (Cîrstea, 2014).

Financial and political accountability demands a broader and more complete accounting system -the consolidated financial statement (CFS) - to make decisions and improve accountability (Carini and Teodori, 2019). CFS also serves to increase accountability and transparency towards internal and external stakeholders. CFS is now an essential element of the public-sector financial reporting in OECD countries in modern financial management 
systems (Bergmann et al., 2016). However, CFS is a relatively recent development within the public sector, and still, there are only a limited number of countries that have introduced CFS in the public sector at the central and local level (Grossi and Pepe, 2009). Although few countries have implemented the CFS (Cîrstea, 2014), independent bodies and experts are able to offer the necessary input to carry out the changes; for example, the International Public Sector Accounting Standards Board (IPSASB). In some countries (e.g. Australia, the USA, Canada, Sweden, the UK, New Zealand), accounting standards for the consolidated financial report in the public sector have already been established (Grossi and Pepe, 2009). Vietnam is a developing country with its own political and institutional characteristics. Nevertheless, Vietnam has issued Decree No. 25/2017/ND-CP regulating the preparation and disclosure of the public-sector financial reports and began its adoption from January 1, 2018. However, while there are no public accounting standards there are many different accounting regimes applicable to the public-sector entities in Vietnam, such as the accounting regime for administrative and non-business units, the accounting regime in the field of social insurance, the treasury accounting regime and the accounting regime at the ward and commune levels. This will undoubtedly make it difficult to prepare CFS for the public sector in Vietnam. At present, there are almost no studies about CFS in relation to the public sector in Vietnam. More research is therefore needed to clarify the benefits as well as the challenges and difficulties of implementing CFS in the public sector in Vietnam.

At the international level, the International Public Sector Accounting Standards Board issued IPSAS 6, recently superseded by IPSAS 35, according to which, CFS represents the financial statements of an economic entity, in which the assets, liabilities net assets/equity, revenue, expenses, and cash flows of the controlling entity and its controlled entities are presented as those of a single economic entity (IPSASB, 2017). Accordingly, the public-sector CFS is a key factor within public-sector accounting. In this context, and there is still a need for more empirical and theoretical research based on a separate research agenda allowing that the public sector is organizationally specific (Santis et al., 2018). Adopting a structured literature review methodology, Santis et al. (2018) investigate how the CFS literature is developing and what its focus is. They find that current studies dealing with CFS of the public sector refer mostly to only five major topics: the definition of the consolidation area; the identification of the reporting entity; the privates public sector accounting standard dichotomy; the relationship with the statistical rules; and the usefulness of CFS (Santis et al., 2018). Through a study of relevant literature, they show that very few studies use quantitative methods to identify and measure the impact of factors on either the implementation or expected performance of CFS of the public sector in each country.

This study makes two main contributions. First, we use the qualitative research method through interviews with experts who are knowledgeable about public accounting. In this step, we seek to synthesize and analyze the main benefits as Vietnam performs CFS. We reveal the challenges and difficulties for the implementation of CFS in Vietnam in the near future. These findings will assist Vietnamese policy-makers in reviewing the implication and preparation of public-sector CFS in the context of Vietnam. Second, this study uses the quantitative research method to identify and measure the effects of expected factors (as a result of the literature review and expert interview) for the implementation of public-sector CFSs in Vietnam.

\section{Theoretical Background}

The CFS in the public sector has gradually become a matter of interest and of current debate both for academics and practitioners. Commander theory as posited by Goldberg (1965) shows that ownership and control are separate notions. That is, ownership is a legal condition, but control is a function that can only be exercised by human beings. Senior managers such as ministers or department heads have the right to control the resources for which they have responsibility. At the same time, they must also be accountable for such resource management before the resource owners. This perspective can help to explain whether certain environmental factors constitute significant impediments to the cross-sector transfer of the consolidated financial reporting practice to the public sector. Specifically, it provides an examination of the beliefs of the top-level and lower-level commanders as to the usefulness of CFS for the purposes of accountability. Public sector officials are responsible for the compilation and the accountant is responsible for the preparation of CFS. Therefore, the results of the implementation of the report will depend on usercommanders (Bergmann and Bietenhader, 2008; Wise, 2010).

In the public sector, providing information on government finances has been regarded as a means of limiting conflict between citizens and politicians and is a part of agency theory (Zimmerman, 1977). In addition, the agency theory offers one possible explanation to why the consolidation in the public and private sector is significant in terms of accountability. It describes the information asymmetry between the agent and the principal and the problem of the pursuit of different power between principal and agent, the agent has to report to the principal. Moreover, in the context of stakeholder theory, CFS can provide relevant and 
undistorted financial information to the internal and external stakeholders (Bergmann et al., 2016). The internal stakeholders, namely politicians and public managers, consider CFS as a useful tool for steering and controlling the direct and indirect provision of public services. CFS might also to be considered useful by external stakeholders (e.g. citizens, international organizations, and rating agencies) since CFS provides a summary of the financial performance of the government as a whole.

CFS may be viewed as one of the most significant accounting techniques of the public sector accounting reforms, in which two or more individual entities are reported as if they are one common entity (Carini and Teodori, 2019). In order to prepare CFS, separate sets of accounting reports are aggregated and certain other adjustments made to have consolidated totals. The financial statements, individual financial statements or consolidated ones, are considered a key accountability tool for different users (Gomes et al., 2019). A focus in this study is whether CFS is a useful tool for the discharge of the accountability for government resources. In other words, what are the main benefits that CFS provide? Cîrstea (2014) recognizes that CFS can bring many advantages to the public sector. Specifically, they increase the transparency and accountability of the government and public property agencies. Previous studies identify the relevance of the public-sector CFS regarding their usefulness for stakeholders. Usefulness consists of providing a more comprehensive picture of the "public group" supporting decision-making processes and, at the same time, ensuring public accountability (Bisogno et al., 2015). CFS is a useful instrument for the government because it presents a clear picture of the current economic status and functioning of public units (Bergmann et al., 2016). Furthermore, recent research by Gomes et al. (2019) found that Portugal and Spain have reformed their national standards to implement the IPSAS for consolidated reporting because it is useful for assessing a government's financial position, performance and cash flows. In sum, CFS are both an accountability tool and a decision-making tool (Carini and Teodori, 2019).

The IPSASB is an independent standard-setting body of the International Federation of Accountants (IFAC) which promulgates accounting standards for the public sector that are based on private sector standards. In May 2000, the IPSASB issued the IPSAS 6, enhancing the quality, consistency, and transparency of financial reporting in the public sector worldwide. In the public sphere, IPSAS 6 aims at establishing provisions for the preparation and presentation of CFS and accounting of controlled entities, jointly controlled entities and associations. The provisions allow for separate financial statements from the controlling entities, ventures and investors. In the private sphere,
IFRS 10 contains some issues that are not included in IPSAS 6. This aspect generates the need to issue a new accounting standard for the public sector regarding the CFS, as well as a review of the existing one. To achieve improvements to IPSAS 6 from the public sector point of view, IPSAS 35 was issued. IPSAS 35 replaces the IPSAS 6 requirements regarding CFS. The amendments to it were influenced by the standards of the private sector, but also by the specificity of the public sector. IPSAS 35 still requires that control is assessed with regard to benefits and power, but the definition of control has changed and the standard now provides considerably more guidance on assessing control. In addition, it introduces the concept of investment entities, which may be applicable to some sovereign wealth funds. In contrast with IPSAS 6 - consolidated and separate financial statements, IPSAS 35 no longer permits an exemption from consolidation for temporarily controlled entities. IPSASs on CFS are issued with the aim to improve the quality of general purpose financial reporting by public sector entities, public system organizations, governments and other non-profit organizations (IPSASB, 2017).

In Vietnam, according to the Decree No. 25/2017/ ND-CP, the CFS of the public sector in Vietnam is prepared and applied for the financial year from 2018, the units tasked with providing the information for the preparation of the government financial reports are: The Ministry of Finance; State Treasury at all levels; agencies managing, performing state budget revenues and expenditures at all levels; agencies managing the assets and capital of the state at all levels; state agencies and organizations using the state budget; agencies and organizations managing non-state budget funds; and public Service units. Accordingly, publiclyowned companies are not included in the scope of the consolidation. The government financial reports in Vietnam are made both nationwide and for the province. The government financial reports must be composed of four types, namely report on the state financial situation, the report on the results of state financial activities, the statement of cash flows, and the notes on state financial statements (Socialist Republic of Vietnam, 2017). Recently, in order to prepare well CFS for public sectors in Vietnam, the Ministry of Finance issued two Circulars guiding in details for preparing CFS, namely Circulars No. 99/2018/TT-BTC and No. 133/2018/TT-BTC (Ministry of Finance, 2018a; Ministry of Finance, 2018b).

However, the benefits for internal and external users and the potential improvement of public sector accounting systems have to be compared with the costs and obstacles involved in the implementation of consolidated financial reporting (such as personnel costs, costs for training and consulting information technology systems, etc.). There are some problems with implementing and using CFS in the public sector, including the 
difficulty of comparing consolidated information across different levels of the government and in defining the scope of consolidation (Santis et al., 2018; Santis et al., 2019). At the same time, the consolidation process requires eliminating the financial effects of the internal operations carried out between a local authority and its subordinate units, so that CFS only reflects external transactions with third parties.

Bergmann and Bietenhader (2008), using a survey in Switzerland, find that there are reasons for not preparing CFS in the public sector, such as the lack of interest or political pressure, the high costs of implementation, the lack of legal obligations, and technical problems. Grossi and Pepe (2009) provide an understanding of the reasons why CFS is not yet widespread in Italian local government or other EU continental countries. To adopt CFS, the local government needs to overcome obstacles that are primarily of cultural, technical as well as of a legal nature. There are cultural obstacles because CFS is still a new task for Italian local authorities. They need to invest more in new technology and training activities in this specific and complex accounting tool. The technical obstacles concern the lack of homogeneity in the financial statements of the single entities included within the area of consolidation. The main problem is that decentralized entities use national private-sector accounting standards which differ from those used by local governments. In addition to technical and cultural difficulties, there are also legal obstacles, because CFS is not compulsory in Italia. Cîrstea (2014) states that the preparation of public sector CFS would have caused a series of problems, namely the lack of homogeneity of the financial statements prepared by controlled entities, the fact that the public sector standards must be different from those for the private one, the lack of professionals, and the lack of the obligation for presenting consolidated reports. Carini et al. (2019) survey the local financial officials in Italy and show that CFS has a positive impact on the managers' decisions and accurately assesses the local performance. Additionally, they find that the difficulties when implementing and preparing CFS are the lack of professional knowledge of financial staff and the costs in applying CFS. Carini et al. (2019) maintain that the preparation of CFS is a very difficult task which may need a long time, but which, nevertheless, contributes to better understanding of the government's financial position. Therefore, Santis et al. (2019) found that CFS implementation should be preceded by a testing period for local governments because of improving employees' skills. Santis et al. (2019) also suggested that central governments should provide technical assistance to local governments through training to facilitate the implementation of CFS. Recently, Chow et al. (2019) conduct an empirical comparative study of consolidated government accounting reforms in the UK, Australia, New Zealand, Canada and Sweden, and show that contextual differences in these countries greatly influence the application and awareness of the usefulness of CFS. Thus, the benefits for the internal and external users and the potential improvement of public-sector accounting systems have to be compared with the costs involved in the implementation of CFS.

\section{Hypothesis Development}

The Accrual Accounting Basis and the Implementation of CFS in the Public Sector

Changing from a cash basis to an accrual basis of accounting has implications for many features of public sector accounting and financial reporting, one of which is the use of accrual-based consolidated financial reporting (Tagesson and Grossi, 2012; Guthrie, 1998). The introduction and presentation of consolidated reports in the public sector are closely connected with the adoption of an accrualbased accounting system, an idea also approved by some researchers (Guthrie, 1998). Public sector accrual basis CFSs, represent a significant role in the whole interconnected set of governments financial statements, that add value to budget information and individual financial statements, helping to understand the whole financial performance and position of the government (assets, liabilities, performance) by providing reliable information (Cîrstea et al., 2017). Furthermore, accrual CFS represents a useful tool for a clear picture of the current economic status and government as a whole (Wise, 2010). In this framework, the promoting of accrual basis reporting provides a realistic picture of the position and performance of the whole public sector, therefore increasing transparency and accountability (Andriani et al., 2010). Therefore, this study proposes the following hypothesis:

$\mathrm{H}_{1}$. - The accrual accounting basis positively influences the implementation of CFS in the public sector in Vietnam.

\section{The Regulatory Environment and} the Implementation of CFS in the Public Sector

Based on contingency theory, Luder (1992) argues that each country should allow its own economic, cultural and political characteristics to provide appropriate legal provisions. Indeed, the characteristics of the political environment of each country are different, which creates differences in the regulatory environment, as legal regulations are instrumental in institutionalizing management perspectives and the administration of the State (Bergmann and Bietenhader, 2008). Furthermore, Grossi and Steccolini (2015) also noted that countries should not fully apply the private sector consolidated financial reporting principles to develop CFS regulations for the public sector, as the public sector has its own characteristics. Especially, 
in an analysis of the barriers to the implementation of CFS in Italian local governments, Grossi and Pepe (2009) points out that the regulatory environment plays a key role. He finds that the lack of specific public sector integration standards is a major barrier for public agencies in the CFS preparation and presentation process. The results of Bergmann et al. (2016) shows that the Organization for Economic Co-operation and Development (OECD) countries have a differentiated approach, so that different legal provisions need to be introduced regarding the methodology and principles for identifying the integrated sector. From the results of this analysis, this study proposes the following hypothesis:

$\mathrm{H}_{2}$. - The regulatory environment positively influences the implementation of CFS in the public sector.

\section{The Accountants' Capacity and the Implementation of CFS in the Public Sector}

Capacity is the characteristic of a person who has the skill, knowledge, and ability to perform a task (Boritz and Carnaghan, 2003). The accountants' capacity is the ability to perform the duties and expected roles of a professional accountant, following the standards that employers and society generally expect (International Federation of Accountants Education Committee, 2001). The capacity of human resources is an important factor in determining the quality of financial reporting information (Xu et al., 2003). In order to generate useful financial information, financial statements must be prepared by qualified staff in the field of financial management and accounting systems. Furthermore, Montesinos and Brusca (2008) argue that the preparation of CFS is a difficult task to accomplish and it takes a long time to prepare the required human resources. Grossi and Pepe (2009) also argue that the lack of qualified staff or staff in CFS is the most common problem and an obstacle to the implementation of consolidated financial statements in many countries. Therefore, this study proposes the following hypothesis:

$\mathrm{H}_{3}$. - The accountants' capacity influences the implementation of CFS in the public sector.

\section{Information Technology and} the Implementation of CFS in the Public Sector

Information technology includes computers (mainframes, small computers), software, databases, networks, e-commerce and other related technologies (Welch and Wong, 2001). According to Salehi and Husini (2011), the development of information technology is not only used in business organizations but also in public sector organizations. The public sector is obliged to develop and take advantage of advances in information technology to improve the financial management and distribution of financial information for public services. CFS is a complex task that requires financial investment to upgrade the appropriate software (Montesinos and Brusca, 2008). Furthermore, Bergmann and Bietenhader (2008) also state that the difficulty of drawing up CFS in the public sector in Switzerland is a technical issue. The technical obstacles are related to the lack of homogeneity in the financial statements of the single entities included within the area of consolidation. At the same time, Grossi and Pepe (2009) points out that CFS is still a new task for Italian local authorities, and that they need to invest more in new technology and in training activities in this specific and complex accounting tool. Therefore, this study proposes the following hypothesis:

$\mathrm{H}_{4}$. - Information technology influences the implementation of CFS in the public sector.

\section{MATERIALS AND METHODS}

\section{Sample and Data Collection}

To achieve the stated research objectives, we apply a mixed-method research in the form of explored mixed designs. Firstly, we present the qualitative research method, then we present the quantitative research method.

Qualitative research methodology is used to identify (both discover and confirm) the impact of factors on the implementation of CFS of the public sector in Vietnam. At the same time, recipients were asked to indicate their views and perceptions on benefits and challenges of the implementation of CFS in Vietnam's public units. This study was conducted by a case study with data collection techniques through group discussions with twenty experts. The study adopted the semistructured level for the questionnaire (with closed questions and open-ended questions). Participants are professionals with a deep understanding of public sector accounting in Vietnam, including lecturers, chief accountants, and accountants with working experience of at least 5 years. Moreover, the questionnaire was pretested and revised by obtaining the opinions of professionals. Then, a completed questionnaire is used for quantitative research in the next section.

In quantitative research, a survey approach was adopted in this study. Questionnaire methods of data collection are common in the investigation of financial reports (Wise, 2010). A purposive sampling technique was chosen as a means of producing a sample that would provide insight as to the implementation of the consolidated financial reporting in Vietnam's public units. The unit of analysis in this paper is each organization. In each organization, we select an organization representative to answer the survey questionnaire. The scope of the survey includes administrative agencies, public service about education, medical industry, cultural, sports and other social 
organizations in the public sector in Vietnam. We sent 200 questionnaires to the survey subjects. Survey respondents are the chief accountants, accountants, managers and others related to the preparation and use of information on CFS. The sampling criteria aim at respondents who have experience and knowledge related to the research topic, which can improve the value of research results.

\section{Measurement Scales}

In the framework, the research model consists of one dependent variable and four independent variables. In general, we applied variables validated in previous research (Santis et al., 2019).

The dependent variable in the research model aims to capture the implementation of CFS of the public sector in Vietnam. This variable is measured using a scale that accords with Socialist Republic of Vietnam (2017) and IPSASB (2017b), including the implementation of four reports in CFS, i.e. the statement of financial position, the statement of financial performance, the cash flow statement, and the notes to the financial statements.

The four independent variables include accrual accounting basis, accounting staff capacity, regulatory environment, and information technology. A scale of four items developed by Ofoegbu (2014) is used to measure accrual accounting basis. The scale for accounting staff capacity is adapted from Indriasih and Koeswayo (2014) with four items including knowledge, computer skill, attitude, and experience. Regulatory environment use is measured following Van (2016) with a scale of four items, i.e. accounting law, budget law, accounting regime and Decree, Circular guiding accounting. To measure the variable of information technology, we use the scale of four items developed by Quynh (2015). The questionnaire used in this study has a scale from one to five, making it a five-point scale. The questionnaire is available upon request.

\section{RESULTS AND DISCUSSION}

\section{Results of Qualitative Research}

Through the interview process, this study gathered feedback from experts focusing on three main aspects. The first relates to the benefits of implementing the public-sector CFS in Vietnam. Experts in Vietnam believe that CFS helps to reveal the financial picture of the entire public sector, so that, users can better understand the assets, liabilities, revenue, costs and cash flow of local and central government. Moreover, they also state that CFS will help users compare financial situations between countries. Thus, CFS helps improve transparency and accountability of the government and agencies that use public resources.

The second aspect relates to the difficulties of implementing the public-sector CFS in Vietnam. In the opinion of the experts, implementing CFS in
Vietnam will face many problems. Firstly, accrual basis accounting has not been applied consistently between accounting regimes of public units. Secondly, the capacity of accountants to understand CFS is limited. Thirdly, although Decree No. 25/2017/ND-CP regulates CFS in the public sector, there is no Circular guiding how to prepare and present CFS. Fourthly, there are no public accounting standards in Vietnam. Lastly, information technology infrastructure is still weak and will find it difficult to integrate the large data for CFS implementation throughout the country.

The third aspect concerns the factors expected to affect the implementation of the public-sector CFS in Vietnam. The results show that all experts (100 percent) agree with the relevance of the factors proposed, namely accrual accounting basis, accounting staff capacity, regulatory environment, and information technology. In addition, experts have contributed additional factors. For example, 20 percent of expert opinion proposes adding the accounting community factor, 20 percent of expert opinion proposes adding an additional integration pressure factor, and 20 percent of expert opinion suggests adding an IPSAS factor. However, we have not included these factors in the research model because the proposed factors are not approved by experts and by previous research supports. Therefore, the regression function is:

ImpCFS $_{1}=a_{0}+a_{1} A C C_{i}+a_{2} C A P_{i}+a_{3} R E G_{i}+a_{4} I T_{i}+\varepsilon_{i}$, (1)

where: the dependent variable is the implementation of CFS in the public sector in Vietnam (ImpCFS $)$.

The independent variables are: $A C C_{i}$ : Accrual accounting basis; $C A P_{i}$ : Accounting staff capacity; $R E G_{i}$ : Regulatory environment; and $I T_{i}$ : Information technology.

\section{Results of Quantitative Research}

The total number of questionnaires sent was 200, of which 135 had valid responses. The survey took place over three months, commencing January 2019. At the end of March 2019, there were 141 responses, of which 119 responses were due to the direct questionnaire and 22 responses by email, reaching a high response rate of 70.5 percent. After excluding incomplete response, the author has 135 valid responses. The accountant in the public sector's group represents the highest percentage of respondents (83.9 percent) followed by the head of the unit (8.7 percent) and the academics (7.4 percent). On working experience, the majority of respondents had over 5 to 10 years (56.3 percent) and between 3 and 5 years of work experience (37.8 percent), 5.9 percent has over 10 years of work experience.

\section{Reliability Analysis}

We apply the Cronbach Alpha test to evaluate the reliability of independent and dependent variables. Observed variables with item-total correlation less 
I: Results of Multiple Scale Analysis

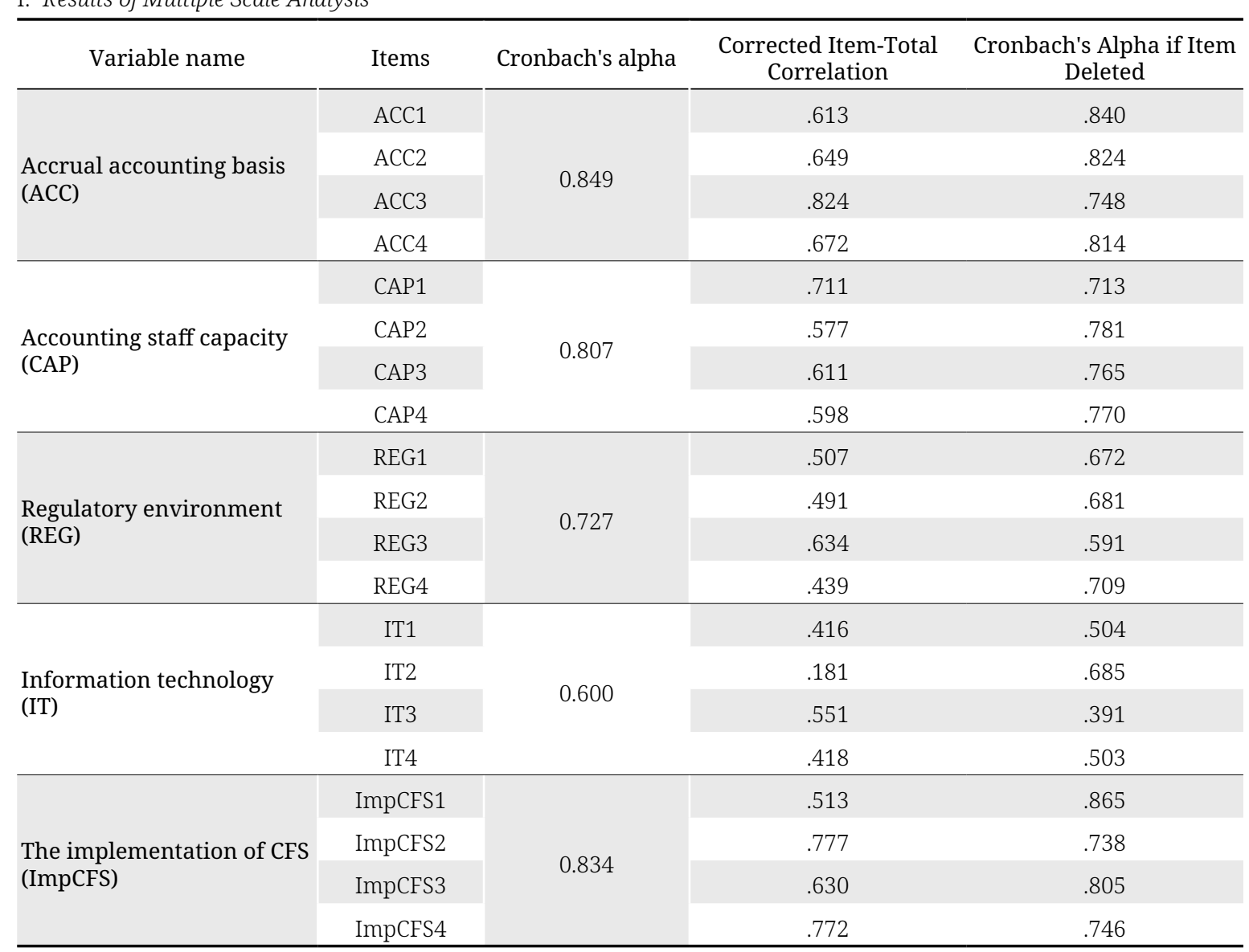

than 0.3 are excluded and the scale is chosen so that the Cronbach Alpha coefficient is 0.6 or greater (Hair et al., 2014a). As summarized in Tab. I, all scales have a Cronbach Alpha coefficient greater than 0.6 and the item-total correlation is greater than 0.3 except for IT2.

Observation variable (IT2) which belongs to the factor of information technology has a Corrected Item-Total Correlation of $0.181<0.3$ so this observation is rejected. When the observation variable IT2 is eliminated, the Cronbach Alpha coefficient of the content scale of the information technology increases from 0.600 to 0.685 . At the same time, the remaining observation variables have Corrected Item-Total Correlation in the range 0.430 to 0.584 , which is greater than 0.3 . Thus, the scales were satisfactory and the observational variables (except IT2) were retained in the exploratory factor analysis (EFA).

\section{The Exploratory Factor Analysis}

After checking the reliability of the scale, the exploratory factor analysis is conducted to determine the underlying factorial structure of the scale and eliminate unrelated items (Hair et al., 2014a; Hair et al., 2014b). The chosen extraction method for factor analysis is the principal components method with varimax rotation. The results are summarized in Tab. II.
II: Synthesized Results of EFA Analysis of Independent Variables

\begin{tabular}{cccc}
\hline No. & Parameters & Value & Satisfying conditions \\
\hline 1 & KMO & 0.736 & $\geq 0.5$ \\
2 & Sig. of Bartlett's Test & 0.000 & $\leq 0.05$ \\
3 & Eigenvalues & 1.393 & $>1$ \\
4 & Cumulative (\%) & $63.563 \%$ & $\geq 50 \%$ \\
\hline
\end{tabular}

Based on the results of EFA that are summarized in Tabs. III, IV, and V, the scales exhibit convergent values or observable variables that represent the concepts to be measured.

Tab. VI describes independent and dependent variable. The total number of observed variables is nineteen items.

In short, the results of Cronbach's alpha coefficient analysis and the EFA extracted four factors confirm the implementation of CFS in the public sector in Vietnam.

\section{Multiple Regression Analysis}

To begin, Pearson correlation among the studied variables are presented in Tab. VII. Positive correlations are found between four factors (accrual accounting basis, accounting staff capacity, regulatory environment, information technology) 
III: Rotated Component Matrixa

\begin{tabular}{lcccc}
\hline & \multicolumn{4}{c}{ Component } \\
\cline { 2 - 5 } & 1 & 2 & 3 & 4 \\
\hline ACC3 & .909 & & & \\
ACC4 & .818 & & & \\
ACC2 & .783 & & & \\
ACC1 & .745 & & & \\
CAP1 & & .847 & & \\
CAP2 & & .790 & & \\
CAP3 & & .750 & & \\
CAP4 & & .736 & & \\
REG3 & & & .834 & .780 \\
REG2 & & & .755 & .675 \\
REG1 & & & .681 & \\
REG4 & & & .563 & \\
IT3 & & & & \\
IT4 & & & & \\
IT1 & & & & \\
\hline Extacton & & & & \\
\hline
\end{tabular}

Extraction Method: Principal Component Analysis.

Rotation Method: Varimax with Kaiser Normalization.

a. Rotation converged in 5 iterations.

and the implementation of CFS in the public sector indicating that these factors show a higher implementation of CFS
IV: Synthesized Results of EFA Analysis of Dependent Variable

\begin{tabular}{clcc}
\hline No. & \multicolumn{1}{c}{ Parameters } & Value & Satisfying conditions \\
\hline 1 & KMO & 0.528 & $\geq 0.5$ \\
2 & Sig. of Bartlett's Test & 0.000 & $\leq 0.05$ \\
3 & Eigenvalues & 2.341 & $>1$ \\
4 & Cumulative (\%) & 58.523 & $\geq 50 \%$ \\
\hline
\end{tabular}

\section{V: Component Matrix}

\begin{tabular}{lc}
\hline & Component 1 \\
\hline ImpCFS2 & .900 \\
ImpCFS4 & .899 \\
ImpCFS3 & .800 \\
ImpCFS1 & .686 \\
\hline
\end{tabular}

We assessed the suitability of the model (Tab. VIII). The results show that the adjusted coefficient of $\mathrm{R}^{2}$ is 0.454 , which means that the linear regression model was constructed in accordance with 45.40 percent of the data and sig value $<0.05$ and $F=28.831$ show that the regression model is consistent with the dataset, and that the variables included in the model are statistically significant at the 5 percent level.

Secondly, we tested the significance of the regression coefficients. The results show that there are four factors with Sig. $\leq 0.05$. All four factors have a similar impact on the expectation for implementing

VI: Summary of Variables after Exploratory Factor Analysis

\begin{tabular}{clll}
\hline No. & \multicolumn{1}{c}{ Variables } & \multicolumn{1}{c}{ Criteria } & Type \\
\hline 1 & Accrual accounting Basis (ACC) & ACC3, ACC4, ACC2, ACC1 (4 criteria) & Independent \\
2 & Accounting staff capacity (CAP) & CAP1, CAP2, CAP3, CAP4 (4 criteria) & Independent \\
3 & Regulatory environment (REG) & REG3, REG2, REG1, REG4 (4 criteria) & Independent \\
4 & Information technology (IT) & IT3, IT4, IT1 (3 criteria) & Independent \\
5 & The implementation of CFS (ImpCFS) & ImpCFS2, ImpCFS4, ImpCFS3, ImpCFS1 (4 criteria) & Dependent \\
\hline
\end{tabular}

VII: Correlation Matrix

\begin{tabular}{|c|c|c|c|c|c|c|}
\hline & & ImpCFS & $\mathrm{ACC}$ & CAP & REG & IT \\
\hline \multirow{2}{*}{ ImpCFS } & Pearson Correlation & 1.000 & & & & \\
\hline & Sig. & . & & & & \\
\hline \multirow{2}{*}{ ACC } & Pearson Correlation & .142 & 1.000 & & & \\
\hline & Sig. & .051 & & & & \\
\hline \multirow{2}{*}{ CAP } & Pearson Correlation & .485 & .000 & 1.000 & & \\
\hline & Sig. & .000 & .500 & . & & \\
\hline \multirow{2}{*}{ REG } & Pearson Correlation & .209 & .000 & .000 & 1.000 & \\
\hline & Sig. & .007 & .500 & .500 & . & \\
\hline \multirow{2}{*}{ IT } & Pearson Correlation & .414 & .000 & .000 & .000 & 1.00 \\
\hline & Sig. & .000 & .500 & .500 & .500 & \\
\hline
\end{tabular}


VIII: Multiple Regression Analysis

\begin{tabular}{|c|c|c|c|c|}
\hline Proposed hypothesis & Standardized Coefficients & t-value & Sig. & Conclusion \\
\hline \multicolumn{5}{|c|}{ Determinants of the implementation of the public-sector consolidated financial statements in Vietnam: } \\
\hline Accrual accounting Basis (ACC) & 0.142 & 2.218 & ** & H1 accepted \\
\hline Accounting staff capacity (CAP) & 0.485 & 7.592 & $* * *$ & H2 accepted \\
\hline Regulatory environment (REG) & 0.209 & 3.274 & $* * *$ & H3 accepted \\
\hline Information technology (IT) & 0.414 & 6.485 & $* * *$ & H4 accepted \\
\hline
\end{tabular}

Statistical significance is indicated by ***,** and $*$ for $1 \%, 5 \%$ and $10 \%$ respectively

CFS of the public sector in Vietnam. In particular, as shown in Tab. VIII, the most influential factor is the factor of accounting staff capacity $\left(a_{2}=0.485\right)$, the second strongest factor is information technology $\left(a_{4}=0.414\right)$, the third strong factor is regulatory environment ( $a_{3}=0.209$ ), while accrual accounting basis is the least significantly $\left(a_{1}=0.142\right)$. To test multi-collinearity, we use tolerance and variance inflation factors (VIF). The VIF value of the four factors satisfies the non-self-correlation $(1 \leq \mathrm{VIF} \leq 5)$, so there is no multi-collinearity.

In short, we determine four factors affecting the implementation of CFS in the public sector in Vietnam. The results of this study support the conclusions from previous studies. Thus, the capacity of human resources is one of the important factors in determining the quality of financial reporting information (Xu et al., 2003). For example,
Wise (2010) argues that technical infrastructure and human resources are important to prepare for the process of preparing public sector financial reporting because these sources are required for making the reports. In the context of Italian local governments, Grossi and Pepe (2009) points out that the regulatory environment plays a key role. Luder (1992) based on Contingency theory, argues that each country should allow its own economic, cultural and political characteristics to provide appropriate legal provisions. We conclude that accrual accounting improves the comparability of the financial performance between jurisdictions and provides greater accountability of public resources, as the financial data becomes more transparent, so that, accrual accounting facilitates the consolidation of financial statements (Christiaens et al., 2010).

\section{CONCLUSION}

The majority view of research and accounting experts think that the implementation of CFS in the public sector has many benefits, including a financial clarification of the overall public sector. With CFS, information users can anticipate a better understand of the public sector's assets, liabilities, revenues, costs, and cash flows (Santis et al., 2018). Nevertheless, Vietnam, as other countries in the world, will face difficulty when implementing CFS. Some typical difficulties include human resources, infrastructure, financial resources (Cîrstea, 2014).

The results of the quantitative analysis of this paper showed that the implementation of CFS of the public sector in Vietnam was influenced by four factors. Specifically, the expectation is that accounting staff capacity will have the strongest impact on CFS. The next important factor is information technology, followed by regulatory environment and applied accounting basis. Accordingly, Vietnam in seeking to implement CFS for the public sector, will need to focus on the capacity of its accountants. Accountants must have a clear understanding of CFS. In addition, Vietnam must upgrade its information technology system, using data integration software. Vietnam must also revise the accounting regimes currently applied to different public entities and require the introduction of an accounting standard for the public sector based on accruals.

\section{Implications}

This study has theoretical implications. First, the findings from this study support the contingency theory (Luder, 1992). Thus, the study provides evidence that the regulatory environment is a countryspecific factor, and which should be noted when applying IPSAS 35 (IPSASB, 2017) to guide CFS. Second, this study provides empirical evidence of the factors that will affect the implementation of CFS in the public sector in Vietnam.

Besides its theoretical implications, this study provides guidance to public sector managers and the Ministry of Finance who are preparing for the implementation of the public-sector CFS in Vietnam. Firstly, managers of public agencies need to be aware of the benefits and disadvantages of the implementation of CFS. Managers need to raise their awareness of CFS. And managers should focus on the regular training of professional accounting staff by facilitating time and funding. 
For example, Circular 107 has just issued that managers should give all accountants appropriate training, and should not limit the number of participants. At the same time, public units need to strengthen the application of information technology, and upgrade their computer network systems, and investment accounting software. Secondly, the state needs to improve the legal environment. Specifically, the Ministry of Finance should issue accounting standards for Vietnam's public sector. At present, the public sector exists across many different accounting regimes, which makes it difficult to synthesize data when implementing CFS. Public service and administration units are currently under taking accounting system changes under Circular 107/2017/TT-BTC (Ministry of Finance, 2017). The application of Circular 107 will facilitate the process of preparing CFS for the entire public sector in Vietnam. Therefore, the Ministry of Finance should amend the accounting regimes of public units to conform to Circular 107. This will make it easier to synthesize the data when they will have the same basis as the accrual basis. Next, The Ministry of Finance should issue a circular to provide detailed guidance for the implementation of the Decree No. 25/2017/ND-CP. This Circular should provide detailed guidance on the scope of consolidation and the method of consolidation.

\section{REFERENCES}

ADHIKARI, P. and MELLEMVIK, F. 2011. The rise and fall of accruals: A case of Nepalese central government. Journal of Accounting in Emerging Economies, 1(2): 123-143.

ANDRIANI, Y., KOBER, R. and NG, J. 2010. Decision usefulness of cash and accrual information: public sector managers' perceptions. Australian Accounting Review, 20(2): 144-153.

BERGMANN, A. and BIETENHADER, D. 2008. Practises and opinions on consolidated financial reporting in Swiss cities. Workshop on Whole of Government Financial Reporting: International Trends. The University of Siena, Italy.

BERGMANN, A., GROSSI, G., RAUSKALA, I. and FUCHS, S. 2016. Consolidation in the public sector: methods and approaches in Organisation for Economic Co-operation and Development countries. International Review of Administrative Sciences, 82(4): 763-783.

BISOGNO, M., SANTIS, S. and TOMMASETTI, A. 2015. Public-Sector consolidated financial statements: An analysis of the comment letters on IPSASB's exposure draft No. 49. International Journal of Public Administration, 38(4): 311-324.

BORITZ, J. E. and CARNAGHAN, C. A. 2003. Competency-based education and assessment for the accounting profession: A critical review. Canadian Accounting Perspectives, 2(1): 7-42.

CARINI, C., GIACOMINI, D. and TEODORI, C. 2019. Accounting reform in Italy and perceptions on the local government consolidated report. International Journal of Public Administration, 42(3): 195-204.

CARINI, C. and TEODORI, C. 2019. Making financial sustainability measurement more relevant: An analysis of consolidated financial statements. In: Financial Sustainability of Public Sector Entities. Springer.

CHOW, D. S. L., POLLANEN, R., BASKERVILlE, R., AGGESTAM-PONTOPPIDAN, C. and DAY, R. 2019. Usefulness of consolidated government accounts: A comparative study. Public Money and Management, 39(3): 175-185.

CHRISTIAENS, J., REYNIERS, B. and ROLLÉ, C. 2010. Impact of IPSAS on reforming governmental financial information systems: a comparative study. International Review of Administrative Sciences, 76(3): 537-554.

CÎRSTEA, A. 2014. The need for public sector consolidated financial statements. Procedia Economics and Finance, 15: 1289-1296.

CÎRSTEA, A., NISTOR, C. S. and TIRON TUDOR, A. 2017. Consolidated financial statements-a new challenge for the public sector administration. Journal of Economic and Administrative Sciences, 33(1): 46-65.

GOLDBERG, L. 1965. An inquiry into the nature of accounting. American Accounting Association Monograph No. 7. Menasha, WI: George Banta Company, Inc.

GOMES, P., BRUSCA, I. and FERNANDES, M. J. 2019. Implementing the international public sector accounting standards for consolidated financial statements: facilitators, benefits and challenges. Public Money and Management, 39(8): 544-552.

GROSSI, G. and PEPE, F. 2009. Consolidation in the public sector: a cross-country comparison. Public Money and Management, 29(4): 251-256.

GROSSI, G. and STECCOLINI, I. 2015. Pursuing private or public accountability in the public sector? Applying IPSASs to define the reporting entity in municipal consolidation. International Journal of Public Administration, 38: 325-334.

GUTHRIE, J. 1998. Application of accrual accounting in the Australian public sector-rhetoric or reality. Financial accountability and management, 14(1): 1-19. 
HAIR, J. F., BLACK, W. C., BABIN, B. J. and ANDERSON, R. E. 2014a. Exploratory factor analysis. In: Multivariate data analysis. $7^{\text {th }}$ Edition. Harlow: Pearson.

HAIR, J. F., BLACK, W. C., BABIN, B. J. and ANDERSON, R. E. 2014b. Multivariate data analysis: Pearson new international edition. Essex: Pearson Education Limited.

INDRIASIH, D. and KOESWAYO, P. S. 2014. The effect of government apparatus competence and the effectiveness of government internal control toward the quality of financial reporting and its impact on the performance accountability in local government. Research Journal of Finance and Accounting, 5(20): 38-47.

INTERNATIONAL FEDERATION OF ACCOUNTANTS, EDUCATION COMMITTEE. 2001. Competencebased approaches to the preparation and work of professional accountants. Exposure draft discussion paper. New York: IFAC.

IPSASB. 2017. Handbook of International Public Sector Accounting Pronouncements. Vol. II. New York: International Federation of Accountants.

LUDER, K. 1992. A contingency model of governmental accounting innovations in the political administrative environment. In: Research in Governmental and Nonprofit Accounting. JAI Press Inc.

MINISTRY OF FINANCE. 2017. Guiding the public service and administrative accounting regime. Circular No. 107/2017/TT-BTC. Hanoi.

MINISTRY OF FINANCE. 2018a. Guiding the preparation of general financial statements of state accounting units is the superior accounting unit. Circular No. 99/2018/TT-BTC. Hanoi.

MINISTRY OF FINANCE. 2018b. Guiding the preparation of state financial statements. Circular No. 133/2018 /TT-BTC. Hanoi.

MONTESINOS, V. and BRUSCA, I. 2008. Whole of government financial reporting: fashion or necessity. Workshop on whole of government financial reporting: International trends. Siena, Italy.

OFOEGBU, G. N. 2014. New public management and accrual accounting basis for transparency and accountability in the Nigerian public sector. IOSR Journal of Business and Management, 16(7): 104-113.

QUYNH, N. N. 2015. Determining the factors affecting the application of international public accounting standards: "Report of cash flow" into Vietnam. Masters thesis. University of Economics Ho Chi Minh City.

SALEHI, M. and HUSINI, R. 2011. A study of the effect of information technology on internal auditing: Some Iranian evidence. African Journal of Business Management, 5(15): 6168-6178.

SALEHI, M. and TORABI, E. 2012. The role of information technology in financial reporting quality: Iranian scenario. Business Excellence-Poslovna izvrsnost, 6(1): 115-126.

SANTIS, S., GROSSI, G. and BISOGNO, M. 2018. Public sector consolidated financial statements: a structured literature review. Journal of Public Budgeting, Accounting and Financial Management, 30(2): 230-251.

SANTIS, S., GROSSI, G. and BISOGNO, M. 2019. Drivers for the voluntary adoption of consolidated financial statements in local governments. Public Money and Management, 39(8): 534-543.

SOCIALIST REPUBLIC OF VIETNAM. 2017. Decree on state financial reports. No. 25/2017/ND-CP. Hanoi.

TAGESSON, T. and GROSSI, G. 2012. The materiality of consolidated financial reporting-an alternative approach to IPSASB. International Journal of Public Sector Performance Management, 12(2): 81-95.

VAN, C. T. C. 2016. Study the factors affecting the construction of Vietnamese public accounting standards in the context of applying international public accounting standards. Doctoral thesis. University of Economics Ho Chi Minh City.

WELCH, E. W. and WONG, W. 2001. Global information technology pressure and government accountability: the mediating effect of domestic context on website openness. Journal of Public Administration Research and Theory, 11(4): 509-538.

WISE, V. 2010. Theory and accountability: The case of government consolidated financial reporting. International review of business research papers, 6(5): 82-97.

XU, H., HORN NORD, J., DARYL NORD, G. and LIN, B. 2003. Key issues of accounting information quality management: Australian case studies. Industrial Management and Data Systems, 103(7): 461-470.

ZIMMERMAN, J. L. 1977. The municipal accounting maze: An analysis of political incentives. Journal of Accounting Research, 15: 107-144.

Contact information

Trang Cam Hoang: hoangcamtrang@tdtu.edu.vn 